\title{
Unique Growing Rod Treatment with Prior Foundation Surgery for Spondylo-Epi-Metaphyseal Dysplasia with Severe Kyphoscoliosis: A Case Report
}

\author{
Takafumi Chiba, Satoshi Inami, Hiroshi Moridaira, Daisaku Takeuchi, Yutaka Nohara and Hiroshi Taneichi \\ Department of Orthopaedic Surgery, Dokkyo Medical University School of Medicine, Shimotsuga, Japan
}

\begin{abstract}
Keywords:
early-onset scoliosis, growing rod, prior foundation surgery, staged surgery, severe spinal deformity, SEMD

Spine Surg Relat Res 2020; 4(3): 284-286

dx.doi.org/10.22603/ssrr.2019-0077
\end{abstract}

Spondylo-epi-metaphyseal dysplasia (SEMD) is a group of disorders involving the vertebrae as well as the epiphyzes and metaphyzes of long bones ${ }^{1)}$. Kyphoscoliosis is a wellknown clinical feature. SEMD with joint laxity's prognosis is poor due to respiratory failure from severe kyphoscolio$\mathrm{sis}^{2}$. We report a rare case with severe kyphoscoliosis due to SEMD who was successfully treated by growing rod (GR) surgery.

A four-year-old girl was referred to our institute with a progressive kyphoscoliosis. She was born at 40 weeks with a low birth weight (2017 g). Pectus excavatum was recognized at birth. Congenital dislocation of the hip was found at one month. Then, at three months, kyphoscoliosis was observed, and she was diagnosed with SEMD with joint laxity. Joint laxity was seen at the thumbs, wrists, knees, and elbows. Body height and weight at the first visit were $79 \mathrm{~cm}$ and $11 \mathrm{~kg}$, respectively. Initial radiography showed $76^{\circ}$ thoracic scoliosis, $126^{\circ}$ thoracolumbar scoliosis, $69^{\circ}$ thoracic lordosis and $98^{\circ}$ thoracolumbar kyphosis (Fig. 1). She underwent GR surgery at four-years-old. One-level posterior fusion at the proximal (T3-T4) and distal (L3-L4) anchor sites was performed, i.e., prior foundation surgery (PFS) (Fig. 2). PFS included posterior fusion, using local bone graft, and instrumentation, using hooks or pedicle screws. PFS' purpose is to establish a mechanically secure anchor foundation in advance to prepare for correcting severe deformities. At the time of GR placement (four months after PFS), consolidation was confirmed at each fusion level (Fig. $2 \mathrm{C}$ ). Subsequently, she underwent lengthening procedures at six-month intervals. No external support (e.g., brace) was used during the entire treatment course. Because lower in- strumented vertebra (LIV), using a distraction-based construct, was set at L4, her lumbar lordosis was decreased gradually. To prevent further flat-back deformity, anterior spinal fusion from L2 to L4 was carried out six years after the index surgery (Fig. 3). At 12-years old, she had 14 lengthening procedures with limited benefit, so she underwent a definitive posterior fusion without waiting bone maturity. The final, follow-up radiograph demonstrated $38^{\circ}$ thoracic scoliosis, $33^{\circ}$ thoracolumbar scoliosis, $14^{\circ}$ thoracic kyphosis and $29^{\circ}$ lumbar lordosis (Fig. 4). No implantrelated complications occurred for the treatment duration. Although a pulmonary function test at the final follow-up demonstrated mild restrictive respiratory impairment (VC of $61.6 \%$ and FEV1 of $97.2 \%$ ), she attends school with no restrictions.

Severe thoracic deformity in young children critically interferes with normal lung growth ${ }^{3-5)}$. Failure to develop enough thoracic volume may lead to catastrophic results. Therefore, the important goal of GR treatment is to prevent insufficient thorax growth ${ }^{6}$. Although young children with severe spinal deformity require urgent, growth-friendly surgery, such as GR, there is a high risk of anchor site failure $^{7-10)}$ due to tiny and fragile vertebrae. Enhancing anchor site strength by PFS involves a mechanism in which fourpoint anchors placed into the consolidated foundation can tolerate huge correction forces and remain in place without dislodgement. An interval was set to around four months after PFS for the foundation to be solid. In the present case, GR with PFS successfully achieved effective deformity correction and substantial growth of the spine and thorax, with no implant-related complication for the eight-year treatment

Corresponding author: Satoshi Inami, iinami@ dokkyomed.ac.jp

Received: August 25, 2019, Accepted: October 30, 2019, Advance Publication: December 3, 2019

Copyright (C) 2020 The Japanese Society for Spine Surgery and Related Research 

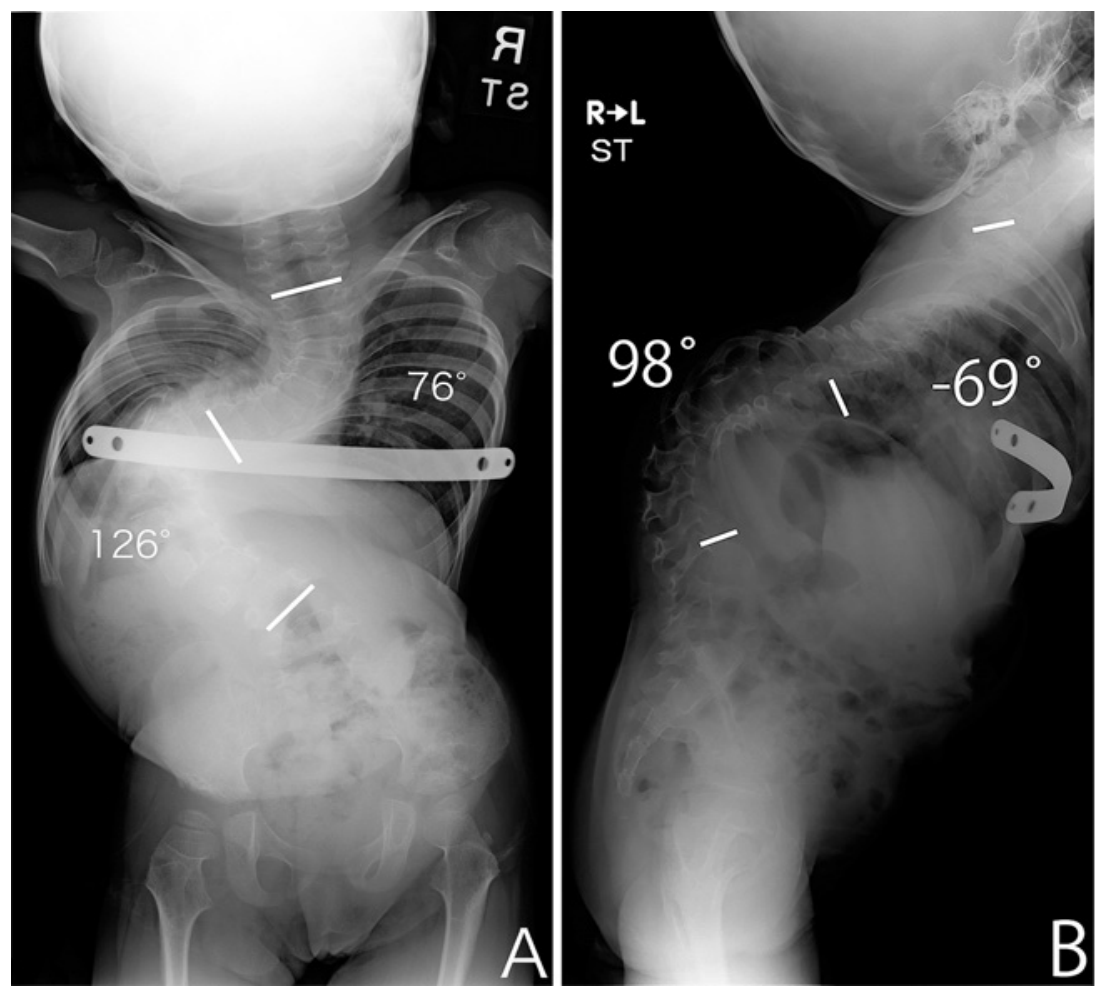

Figure 1. A four-year-old girl with severe kyphoscoliosis due to spondylo-epi-metaphyseal dysplasia (SEMD) with joint laxity. A) Cobb angles of thoracic (T1-T8) and thoracolumbar scoliosis (T8-L4) are 76 and 126 degrees, respectively. B) There is severe thoracic lordosis (T1-T8, -69 degrees) and severe thoracolumbar kyphosis (T8-L3, 98 degrees). Minus sign indicates lordosis.
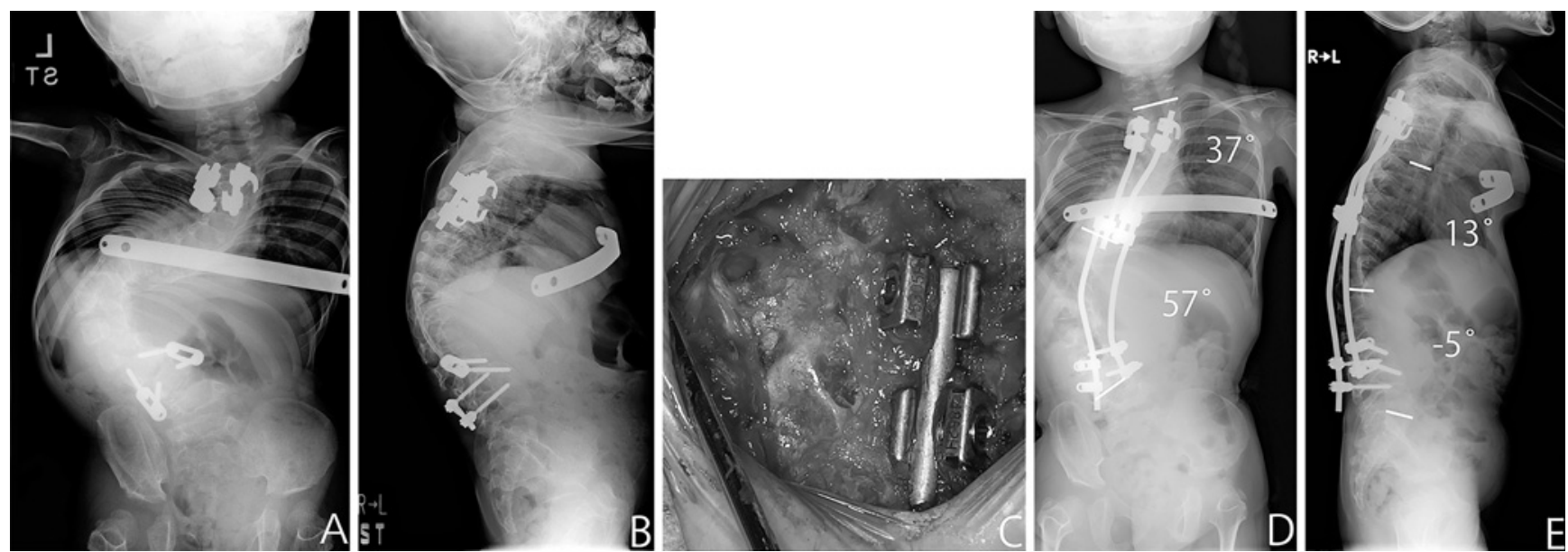

Figure 2. Our unique strategy for growing rod (GR) treatment: prior foundation surgery (PFS). A, B) Posterior fusion at the proximal (T3-T4) and distal (L3-L4) foundation sites was performed before the initial rod placement. C) Four months later, solid posterior arthrodesis was completed at the proximal foundation site. D) Immediately after the initial corrective procedure with rod placement, thoracic (T1-T8) and thoracolumbar scoliosis (T8-L4) were corrected to 37 and 57 degrees, respectively. Correction rates of the major curves after initial corrective surgery were seen at 51\% and 55\%, respectively. E) The sagittal Cobb angles of T5-T12 and T12-S1 have been corrected to 13 and -5 degrees, respectively.

period.

Another issue with GR treatment is that it uses a distraction-based construct; therefore, it is likely to lead to flat-back deformity when the LIV is in the lower lumbar vertebrae. In the present case, not only flat-back deformity but also lumbar curve progression was observed; therefore, anterior fusion was conducted. However, anterior fusion could not make enough lumbar lordosis. Prevention of flatback deformity in patients with GR treatment would be a matter for future study. 

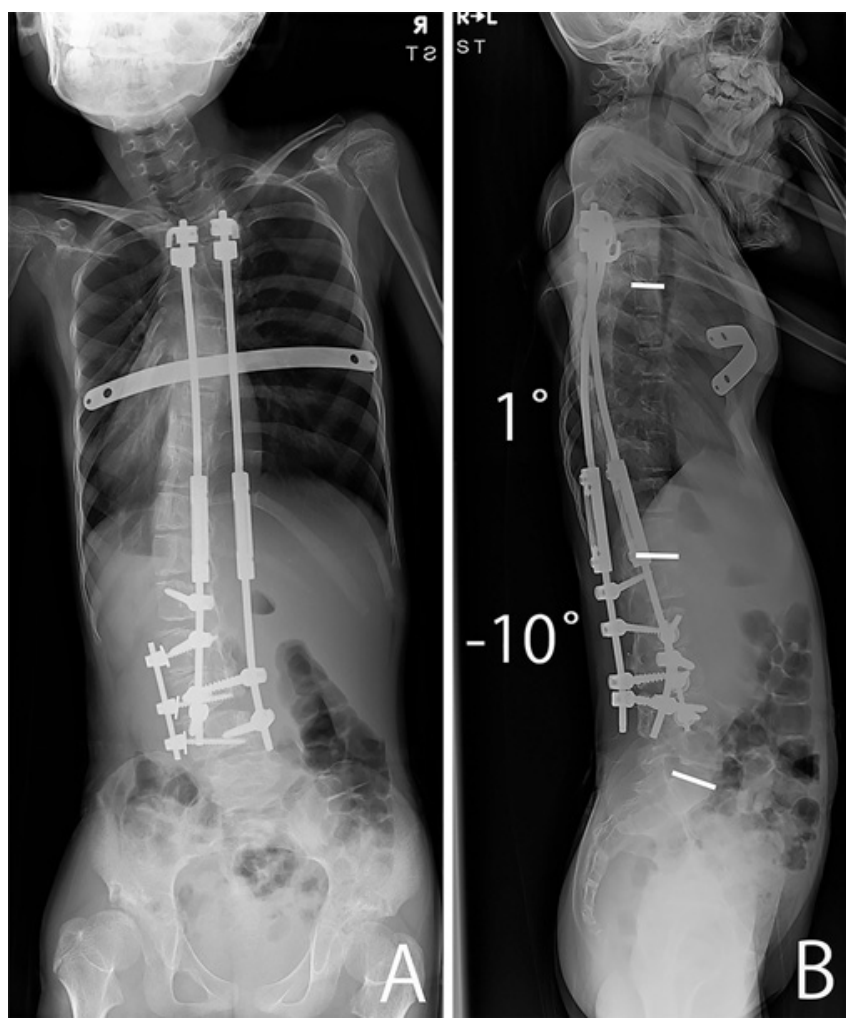

Figure 3. A, B) To correct and prevent flat-back deformity caused by repeated distraction-based procedures, anterior spinal fusion from L2 to L4 is carried out six years after the index surgery.

In conclusion, we successfully achieved GR treatment with PFS in a patient with severe kyphoscoliosis due to SEMD. The patient has obtained well-balanced spinal alignment with acceptable pulmonary function.

Conflicts of Interest: The authors declare that there are no relevant conflicts of interest.

Informed Consent: Informed consent was obtained from the study participant.

\section{References}

1. Valerie CD. Spondylo-epi-metaphyseal dysplasia. Best Pract Res Clin Rheumatol. 2008;22(1):33-44.

2. Beighton P, Kozlowski K. Spondylo-epi-metaphyseal dysplasia with joint laxity and severe, progressive kyphoscoliosis. Skeletal Radiol. 1980;5(4):205-12.

3. Davies G, Reid L. Effect of scoliosis on growth of alveoli and pulmonary arteries and on right ventricle. Arch Dis Child. 1971;46 (249):623-32.
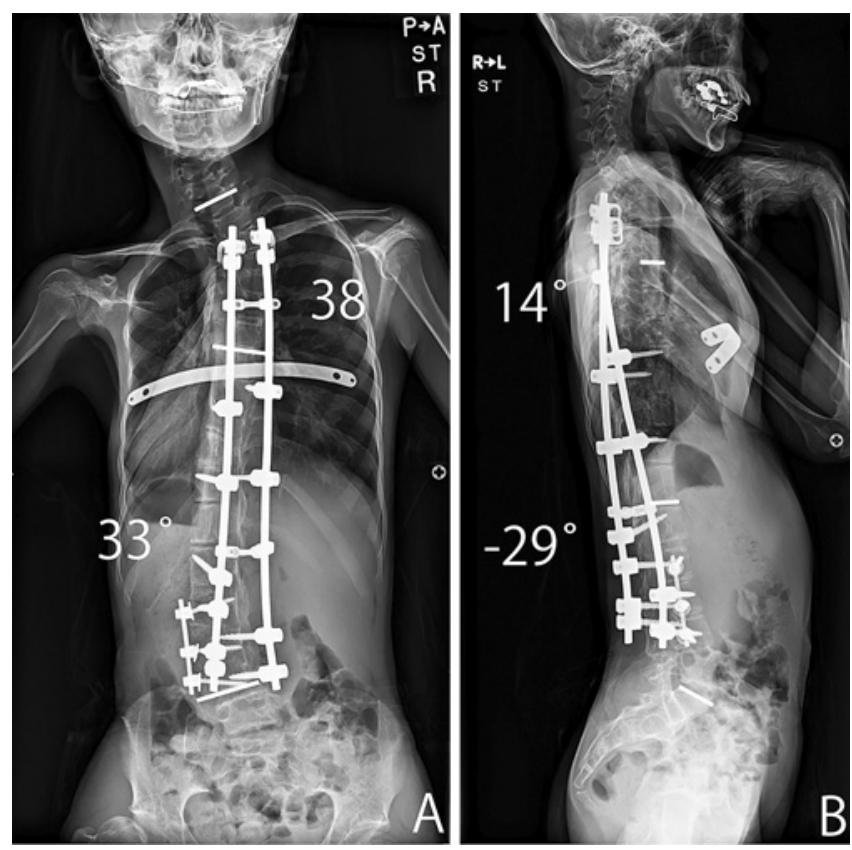

Figure 4. Whole-spine standing X-ray two years after definitive fusion (14 years old). A) Cobb angles of the thoracic and thoracolumbar scoliotic curvatures are 38 and 33 degrees, respectively. B) The sagittal Cobb angles of T5-T12 and T12-S1 are 14 and -29 degrees, respectively.

4. Dunnill M. Postnatal growth of the lung. Thorax. 1962;17(4):32933.

5. Muirhead A, Conner AN. The assessment of lung function in children with scoliosis. J Bone Joint Surg Br. 1985;67(5):699-702.

6. Campbell RM, Mayes TC, Mangos JA, et al. The characteristics of thoracic insufficiency syndrome associated with fused ribs and congenital scoliosis. J Bone Joint Surg Am. 2003;85(3):399-408.

7. Akbarnia BA, Marks DS, Boachie-Adjei O, et al. Dual growing rod technique for the treatment of progressive early-onset scoliosis. Spine. 2005;30(17S):S46-57.

8. Bess S, Akbarnia BA, Thompson GH, et al. Complications of growing-rod treatment for early-onset scoliosis. J Bone Joint Surg Am. 2010;92(15):2533-43.

9. Flynn JM, Tomlinson LA, Pawelek J, et al. Growing-rod graduates. J Bone Joint Surg Am. 2013;95(19):1745-50.

10. Watanabe K, Uno K, Suzuki T, et al. Risk factors for complications associated with growing-rod surgery for early-onset scoliosis. Spine. 2013;38(8):E464-8.

Spine Surgery and Related Research is an Open Access journal distributed under the Creative Commons Attribution-NonCommercial-NoDerivatives 4.0 International License. To view the details of this license, please visit (https://creativeco mmons.org/licenses/by-nc-nd/4.0/). 